\title{
Morte: princípio e fim no De Rerum Natura
}

\author{
MARIA DA GLORIA NOVAK \\ Departamento de Letras Clássicas e Vernáculas \\ Faculdade de Filosofia, Letras e Ciências Humanas \\ Universidade de São Paulo
}

\begin{abstract}
RESUMO: Nada vem do nada, e nada se torna em nada, visto que os princípios dos seres são eternos e imutáveis. Em compensação, tudo o que nasce está destinado a morrer - e também assim o homem e o seu mundo e todos os mundos que houver. $O$ espaço é infinito, a matéria está eternamente em equilíbrio, e tudo muda ao seu tempo. A natureza, de uns seres, constrói outros, e a morte é, assim, fisicamente reconstrução. Para o homem, no entanto, e para sua alma, será a morte o aniquilamento, o fim? Diz o epicurismo que a morte nada é para nós. Será verdade que ele nos aconselha a procurar esse nada? PALAVRAS-CHAVE: Epicurismo, dissolução, renovação, moral, suicídio.
\end{abstract}

A noção de morte no De rerum natura, mais do que pertencer ao tema da morte na poesia latina, pertence, em última análise, à filosofia atomística.

É claro que o De rerum natura é um poema: e o seu Autor é um poeta absolutamente consciente de sua arte (I 945-50).

Esse poema, entretanto, é um documento materialista e epicurista. E se é verdade que o objetivo da física epicurista e lucreciana é moral, igualmente lê-se em Nietzsche que "é na moral que está a chave da física de Demócrito", "o primeiro a explicar o sofrimento da humanidade pela sua vida não científica e pelo seu temor aos deuses" (Souza, 1973, p.359-60). É também o primeiro a afirmar a mortalidade da alma. Ora o atomismo de Leucipo e Demócrito parece a Epicuro a única explicação capaz de garantir ao homem a sonhada paz de espírito, e nele se baseiam os argumentos fundamentais da física epicurista.

Em tudo o que resta dos escritos do Mestre (três cartas, algumas máximas, alguns fragmentos), encontra-se, nítida, a finalidade da sua doutrina: tornar o homem senhor do seu destino, livrá-lo do medo a fim de libertá-lo para a vida, possibilitar-lhe a tranquiilidade da alma, desvendando-lhe as verdadeiras causas dos fenômenos que o atemorizam (Her.\$37; Pyth. §85.96; Lucr. VI 9-41). A idéia viria de Demócrito: o objetivo da ação é a tranqüilidade, que não é idêntica ao prazer como o entendemos: é um estado no qual a alma se mantém calma e estável, sem a agitação de nenhuma superstição ou temor ou qualquer outra emoção ${ }^{1}$.

Epicuro insiste em que é preciso dedicar-se ao estudo, examinar, racionar, pois é possível apreender pelo pensamento a causa dos fenômenos dominantes. Dessa compreensão decorre a felicidade (Her. §78-82): esta é o fim desejado, o fim para o qual tendem todos os seres vivos. 
Acontece, porém, que não é possível atingi-la sem o conhecimento da natureza ( $K D \mathrm{XI}$ XIII), pois só este pode livrar o homem dos seus temores, os maicres dos quais são o medo aos Deuses e o medo à morte, que as duas primeiras máximas do Mestre afastariam: a primeira, afastando a crença na interferência dos Deuses na vida humana; a segunda, a significação terrível da morte.

Assim, quando nos perguntamos que sentido tem esta no De rerum natura, devemos procurar não tanto a sua explicação física mas, sobretudo, o seu sentido moral.

Comecemos, entretanto, pelo seu sentido físico na composição do universo. A seguir, focalizando o homem, vejamos o que é este, o que é sua alma, o que é para ele a morte - a fim de chegar às implicações morais da filosofia do De rerum natura (vale dizer do epicurismo) no que tange à vida humana e ao problema do suicídio.

Há no universo três infinitos, que compõem um todo infinito: átomos, vazio e tempo; infinitos e eternos (Her. $\$ 39$; Lucr. I 951 et seqs $)^{2}$.

$\mathrm{O}$ vazio é uma extensão necessariamente infinita. Compreende os átomos e existe onde quer que estes não estejam, porém não os penetra, pois estes são insecáveis (Her. \$41).

Embora seja infinito o número de átomos, inúmeras, mas não infinitas, como pretendia Demócrito, são as suas formas; e inúmeros mas não infinitos os seus tamanhos. Pequeníssimos, porém, fogem à nossa percepção. $\mathrm{O}$ que os torna insecáveis e indissolúveis é a sua plenitude absoluta (Lucr. I 485-6). As suas qualidades, portanto, são forma, tamanho e peso e tudo o que é necessariamente ligado à forma (Her. §54). Possuem, ainda, quando em composição, a capacidade de continuar em movimento (Her. §43); mas não possuem nem cor, nem odor, nem sabor, nem temperatura, nem sensibilidade (Lucr. II 865-7).

Os seres formam-se a partir dos seus encontros e, como todos os seres se compõem de átomos e neles se decompõem, nada vem do nada e nada acaba em nada (Lucr. I 149-50.215-6): por isso, a quantidade total de matéria é sempre a mesma (II 296). Visto que esta permanece em agitação incessante, as coisas se renovam sem cessar, e os mortais recebem uns dos outros a vida: "cede sempre a velhice, empurrada pelos novos seres, e é preciso refazer uns dos outros [...]. A matéria é necessária para que se formem as gerações seguintes [...]. Nunca deixará de surgir algo de algo":

\section{[...] sic rerum summa nouatur}

semper, et inter se mortales mutua uiuont

[II 75-6].

Quer isso dizer que nada "volta" ao nada; tudo "volta", mas não ao nada e sim à indiferença da morte e aos corpos primeiros da matéria, que são eternos e sólidos. E, assim como nada volta ao nada, assim também nada vem do nada. Há diferentes combinações dos corpora prima para a formação dos diferentes seres; há uma ordem fixa de acordo com a qual tudo muda ao seu tempo; o espaço é infinito, a matéria está em equilíbrio, e a natureza determina o encadeamento das causas e dos efeitos. As combinações fazem-se de maneira certa e em número finito. Se os elementos se combinassem de todos os modos, seres semelhantes gerariam seres diferentes. Assim, embora os átomos difiram na forma, e difiram também pela mudança dos espaços, das direções, das combinações, dos pesos, dos choques e dos seus movimentos (Lucr. II 725-9.10212), ainda assim as combinações se fazem de maneira certa, e há um número finito de combinações dos átomos infinitos (II 700), embora haja um número infinito de repetições dessas combinações.

Convém lembrar que eles se combinam sponte sua (II 1059). Ora, se o espaço é infinito e há, no espaço, infinitos átomos, se estes se combinam por si mesmos, pode haver outros mundos, outras raças, outros gêneros de feras: 
Se os seres vivos têm semelhantes, por que os não teriam o céu, a terra, o sol, a lua, o mar e tudo o que existe? Realmente, não há um só ser que seja único (Lucr. II 1077 et seqs).

Eternos são apenas os três infinitos e os Deuses. Assim, todos os compostos estão fadados a decompor-se, e toda mudança que faz sair um ser dos seus limites acarreta imediatamente a sua morte:

Nam quodcumque suis mutatum finibus exit continuo hoc mors est illius quod fuit ante

\section{[I670-1].}

O tema do segundo livro do poema é justamente a infinidade dos mundos com a sua perpétua alternância de vida e morte: e toda a explicação lucreciana do universo assenta sobre a afirmação de que nada vem do nada e nada se torna em nada, ou seja, "não é possível criar nem destruir a matéria", mas tudo se transforma (I 262-4).

A terra contém todos os princípios, isto é, contém os corpora prima da água, do fogo, dos animais, dos vegetais (Lucr. II 581-99); em suma, de todos os seres, vivos e inanimados. Os corpos, por sua vez, contêm $n$ princípios de formas diferentes; assim o capim e todos os outros: o corpo animal, por exemplo, e também os corpos inflamáveis, que, no dizer de Lucrécio, devem ao menos possuir elementos que produzam o fogo, a luz e as faíscas, e dispersem ao longe a cinza (II 667-79). Por outro lado, os corpos que têm cor, sabor, odor, obviamente contêm princípios diferentes (II 680-1). E é muito importante observar que mesmo os seres sensíveis se formam de elementos insensíveis:

Nunc ea quae sentire uidemus cumpe necessest

ex insensilibus tamen omnia confiteare

principiis constare [...]

[...]

ex insensilibus [...] animalia gigni [II 865-70],

Agora, tudo o que vemos que sente, é necessário que confesses que tudo, no entanto, consta de princípios insensíveis.

[...] De insensíveis [...] nascem os seres animados.

Por quê? Porque a sensibilidade se liga ao que é perecível (mortali corpore, II 906), e os corpora prima são eternos. Ora, sensíveis, seriam vivos; vivos, seriam mortais - pois vivo e mortal é o mesmo - . A sensibilidade dos átomos derrubaria toda a teoria, que repousa sobre a sua eternidade.

Lê-se, ainda, no segundo livro do De rerum natura que os homens são filhos do éter e da terra, e que tudo o que vem do céu volta ao céu, e tudo o que vem do pó volta ao pó (II 991). Assim, a morte não destrói os corpos reduzindo ao nada os seus elementos: apenas lhes dissolve a união e forma outras combinações (II 1004). De fato, como afirma igualmente Empédocles (um dos modelos poéticos de Lucrécio), "não há criação de nenhuma entre todas (as coisas) mortais, nem algum fim em destruidora morte, mas somente mistura e dissociação das (coisas) misturadas" (DK 31 B 8). E por existirem os átomos em número infinito é que pode perdurar a querra dos princípios por toda a eternidade. Átomos provêem a todas as necessidades: corpos se criam, crescem e se desintegram na luta dos contrários; mas, à mesma altura, outros corpos estão-se formando e começam a crescer. Assim como os movimentos destruidores não podem vencer definitivamente, assim os movimentos que garantem o nascimento e o crescimento dos corpos não podem garantir à criação uma duração eterna (II 522 et seqs):

Nunc hic, nunc illic superant uitalia rerum, et superantur item [...] [II 575-6].

A própria terra, em processo de enfraquecimento está destinada a morrer (II 1122-74; V 91 et seqs). 
Quanto ao homem, é um ser da terra e nasce e vive e morre como todos os outros seres vivos. Pertence à natureza e esta nada mais quer para ele senão um corpo sem dor e um espírito sem inquietação e sem medo; não a imortalidade. Ora, lê-se no De rerum natura, como também na Carta a Heródoto (\$63), que a alma é corpórea. De fato, é parte do corpo e não uma disposição vital deste (III 94-100). É guardada pelo corpo e, ao mesmo tempo, vela pela sua segurança; e são inseparáveis na vida como são inseparáveis o incenso e o seu odor (III 324-41).

Dedica o Poeta nada menos de quatrocentos e treze versos do seu terceiro livro (417-829) a provar a mortalidade da alma. Esta compõe-se de corpos diminutos e, tênue como o fumo, dissipa-se no ar ou se destroça no próprio corpo. Entretanto, são a tal ponto conexos que não podem nem sentir nem viver separadamente. Por outro lado, a evidência mostra que a alma cresce e se fortalece com o corpo e sofre também doenças, preocupações, tristeza e medo. Pode ser conturbada, abalada, curada pela medicina. E pode ser mutilada ou destruída aos poucos. Assim, é preciso atribuir-lhes não só origem comum senão também fim comum.

Há um aspecto interessante que é o das leis naturais. Há em toda a natureza uma ordem que determina ambiente e lugar de cada ser, e há uma força determinante das características das espécies. Ora, se imortais, as almas contrariariam as leis da continuidade das espécies pois, se passassem de um a outro corpo, os costumes dos seres vivos se confundiriam. Aliás, se passam, por que não podem lembrar-se de vida anterior? E como podem tornar-se, de sábias, estultas, imprudentes, inexperientes? Nem se vê razão pela qual almas imortais quisessem voltar aos corpos, ou modo pelo qual construíssem a sua morada ou ficassem à espera de corpos nos quais pudessem entrar. Se imortais, como podem ser tão conexas com o corpo, que é mortal? Enfim, imortais, não deplorariam o dissolver-se morrendo, nem temeriam, como parecem temer, a ruína de sua morada.

O Poeta expõe três dezenas de argumentos e os resume em poucas palavras: a alma não tem as características da imortalidade: não é impenetrável como os corpos primeiros da matéria, não é intangível como o vazio, não é infinita no espaço como a suma das sumas e, pois, não está ao abrigo das causas de destruição (III 806-18).

Toda a ética epicurista e lucreciana é sobre esta premissa em que se apóia: a alma é mortal e, portanto, a morte nada é para nós:

\section{Nil igitur mors est ad nos [...] [III 830].}

Apóia-se o Poeta no segundo princípio do Tetraphármakon de Epicuro (KD I-IV) e na Carta a Meneceu (\$124-6) - ho thánatos oudèn pròs hemãs (KD II); medèn pròs hemãs eínai tòn thánaton (Men. §124); ho thánatos outhèn pròs hemãs (Men. §125) - e focaliza o medo instintivo à morte e à insensibilidade, o desejo de prolongar os prazeres da vida e, menos, o medo ao Aqueronte. Insiste o Poeta em que a morte é ausência de sensação, de dor, de angústia; lei comum, inevitável, eterna.

Pois bem. A morte nada é para nós, ainda que a não entendamos como tal. E assim como nada sentíamos antes de nascermos, assim também nada mais sentiremos quando não mais existirmos, depois que se houverem separado corpo e alma que ora se combinam de modo a formar a unidade que somos (III 832-41). Na verdade, como diz o Mestre, a morte não nos diz respeito, pois quando existimos não está presente e quando está presente já não existimos: só atinge o homem aquilo que o atinge vivo, como também afirma o De rerum natura (III 861), porque o bem e o mal residem na sensação. Ora, a morte é privação desta: assim não tem relação nem com os vivos nem com os mortos. É verdade que o morto ficará eternamente morto, mas a eternidade nada é para ele, uma vez que ele não tem consciência na morte, nem memória. As idéias de Epicuro a respeito da morte podem haver sido inspiradas também por Pródicos de Céos, e contrariam frontalmente as de Platão (Wisniewski, 1956, p.32-40). 
Também é verdade que, infinito o tempo, infinito o espaço, infinito o número de átomos, inúmeras as suas possibilidades de combinação, infinito o número de repetições possíveis da mesma combinação, estes semens que nos compõem muitas vezes podem ter estado (e muitas vezes poderiam vir a estar) na mesma ordem em que agora estão; entretanto, nenhuma importância teria isso para nós, visto que teria sido interrompida a nossa memória, e a interrupção da cadeia da memória significa interrupção da vida. Portanto, ainda que, após a nossa morte, o tempo recolhesse a nossa matéria e a reconduzisse ao modo como agora se encontra, e de novo nos viesse a ser dada a luz da vida, isso não nos diria respeito, uma vez interrompida a nossa lembrança (III 847-51).

Assim, diz o Poeta, nada na morte deve ser temido por nós, pois não pode ser infeliz quem não existe e, depois que a morte imortal nos arrebata a vida mortal, estar morto é o mesmo que não haver nascido (III 866-9).

Lucrécio diz textualmente "morte imortal" e "morte eterna":

Mortalem uitam mors inmortalis ademit [III 869], Mors aeterna tamen nihilo minus illa manebit [III 1091].

De fato, a morte, significando "ausência de vida", é anterior à vida e a esta se segue: por isso é eterna.

Pois bem. A morte é imortal e eterna e ninguém desperta, uma vez que o encontrou a fria cessação da vida (III 929-30).

Entretanto, visto que nada acaba em nada, e visto que a matéria é necessária para que se formem as gerações seguintes, e visto que nunca deixará de surgir algo de algo, a morte, situada no limiar entre o fim e o princípio, não é, fisicamente, o fim absoluto.

E psicologicamente? E a morte como fim da vida?

Ora, não há negar, diz o Autor de De rerum natura, a morte é, seguramente, o fim para o ser vivo: é o fim do sentimento e da memória. Nada lhe resta : nem amor, nem desejo, nem alegria, nem saudade, nem dor, nem mal. Nada. Pela morte a vida se reduz a um sono sem sonhos e à quietude. Insensível e inconsciente volta aos corpos da matéria, sono eterno que nada tem de horrível e assustador (III 976).

Não existem os castigos infernais. Em vez de temer o Aqueronte, precisamos, isto sim, combater os nossos medos, as nossas paixões, as nossas ambições. Essa é a idéia no De rerum natura. Vivemos atormentados pelo desejo de poder, pelo desejo de ter e, o que é aberrante para o epicurismo, lutamos como se fôssemos viver eternamente ou, numa ânsia irracional, como se o nosso poder fosse capaz de ultrapassar a nossa vida. E não nos lembramos de que também esta não nos pertence. Isto mesmo diz Tito Lucrécio Caro: a vida a ninguém é dada como propriedade, mas a todos para o uso:

\section{uitaque mancipio nulli datur, omnibus usu [III 971].}

Ao mesmo tempo em que procura livrar-nos do temor da morte, o Poeta mostra-nos as nossas verdadeiras dimensões: cada um de nós é germe e criatura. Materiais, pertencemos à natureza e pela nossa morte participamos da renovação dos seres e das coisas. O nosso corpo é um microcorpo no universo. O tempo da nossa vida, um átimo na eternidade. E, se temos de morrer, por que rebelar-nos contra o que é natural e inevitável? Por que não aceitar a eternização do sono? Mergulhados nele, pouco se nos dará que venha a eternizar-se!

Aí está: por que não aceitar a morte?

Daí a entenderem os estudiosos que o epicurismo aconselha o suicídio vai um passo.

Epicuro é um dos grandes exemplos de coerência no mundo ocidental, mas a sua doutrina sofreu, logo no primeiro século a.C., uma deturpação que tem percorrido os séculos, apesar do poema lucreciano, também do primeiro século a.C. Aliás, a interpretação do poema é, às vezes, até 
forçada para concordar com as falsas idéias que se difundiram desde (por que não dizer?) Cícero e Horácio.

O primeiro, a partir de 54, move uma guerra sem tréguas contra a filosofia do Jardim. Nessa guerra, não menciona o De rerum natura. Na verdade, só uma vez o mencionou: em carta ao irmão (II 9,3), em 54, provavelmente logo após terminar a leitura do poema. E é a partir de então que se desencadeia a sua oposição à doutrina de Epicuro.

O segundo é um poeta: escreve o que lhe vem à cabeça. Algumas vezes até expressa lindamente conceitos de bom-senso que são, por coincidência, ou não, os do epicurismo. Outras vezes, falseia os conceitos, e foi ele quem lançou sobre os epicuristas a pecha terrível que nunca mais os abandonou (Epist. I 4, 15-6).

Ao confrontar o que sabemos da vida e da morte de Epicuro com o que temos de suas idéias, impressionou-me sempre a acusação de ateísmo que sobre ele pesa, e o atribuir-se-lhe algo como uma permissão para o suicídio. E o fato de que se leia (ou se pense ler) igual permissão no poema do mais genial dos seus discípulos e, mais, o pesar sobre esse discípulo uma acusação de suicídio, mostraram-me a necessidade em que estamos de precisar bem esse ponto, que me parece não coincidir com o espírito de uma filosofia cujo bem maior é a amizade.

Analiso o que resta dos escritos do Mestre e analiso o De rerum natura, em busca de dados que possam levar-me a confirmar a veracidade da afirmação. O que encontro são os passos que têm levado estudiosos de todos os tempos a crer que o epicurismo aconselha o homem a abandonar a vida pelas próprias mãos.

Comecemos pelo De rerum natura.

Primeiro passo (III 938-9):

Cur non ut plenus uitae conuiua recedis aequo animo capis securam, stulte, quietem?

Segundo passo (III 943):

Non potius uitae finem facis atque laboris?

Terceiro passo (III 1039-41):

Denique Democritum postquam matura uetustas

admonuit memores motus languescere mentis, sponte sua leto caput obuius optulit ipse.

É imprescindível, ao meu ver, examinar os contextos em que se inserem esses documentos.

Dos seis livros do De rerum natura, um, o terceiro, diz respeito particularmente à natureza da alma e ao sentido da vida e da morte. Está assim constituído:

1. invocação a Epicuro (versos 1-30);

2. proposição (31-93);

3. argumentação (94-1075);

4. epílogo (1076-1094).

Desejo fixar-me na terceira parte da argumentação, loucura do medo à morte (830-1075), visto que a ela pertencem os três documentos mencionados.

Depois de discorrer sobre a natureza da alma (composição, localização e funções) e de apresentar as provas da sua mortalidade, o Poeta, evidentemente em vista da mortalidade do espírito e da alma, conclui, como vimos:

Nil igitur mors est ad nos.

Faz ele falar a natureza, e aqui se encontram os dois primeiros documentos citados.

Primeiro documento (933-9):

Quid tibi tanto operest, mortalis, quod nimis aegris

luctibus indulges? Quid mortem congemis ac fles? 
Nam si grata fuit tibi uita ante acta priorque,
et non omnia pertusum congesta quasi in uas
commoda perfluxere atque ingrata interiere,
cur non ut plenus uitae conuiua recedis,
aequo animoque capis securam, stulte, quietem?

O que é tão importante para ti, mortal, para que te entregues a tão grandes aflições e lutos? Por que tanto gemes e choras a morte? Se te foi grata a vida que viveste e que ficou para trás, se não escoaram e se perderam, estéreis, todos os bens como se amontoados num vaso todo furado, por que não te retiras como um conviva satisfeito da vida e não agarras tranqüilamente, estulto, a quietude livre de inquietações?

Ao meu ver, o que a natureza aconselha ao homem nestes versos é partir de boa vontade. Mas partir de boa vontade significaria "provocar a partida"? Ou, antes, aceitá-la como um conviva aceita o fim da festa e a hora de partir?

Segundo documento (940-5):

Sin ea quae fructus cumque es periere profusa, uitaque in offensust, cur amplius addere quaeris, rursum quod pereat male et ingratum occidat omne, non potius uitae finem facis atque laboris? Nam tibi praeterea quod machiner inueniamque, quod placeat, nihil est: eadem sunt omnia semper.

Se, ao contrário, vazou e se acabou tudo o que fruíste, e a vida é odiosa, por que desejas viver ainda mais, para que outra vez tudo se acabe mal e caia estéril por terra? Não admites, antes, o fim da vida e do sofrimento? Além disso, nada há que eu possa maquinar ou encontrar que te agrade: tudo é igual, sempre.

Focalizemos o verso 943:

Nam potius uitae finem facis $^{3}$ atque laboris?

Verso importantíssimo. É o que em geral mais se interpreta como sugestão de suicídio.

O grande problema está no verbo facio, da expressão finem facis: para Ernout, mettre un terme; para os ingleses Munro e Bailey, make an end of, mas também put an end to.

Vejamos:

Ne vaut-il pas mieux mettre un terme à tes jours et à tes souffrances? [Ernout, 1978]; Why not rather make an end of life and trouble? [Bailey, 1950];

Why not rather make an end of life and travail? [Munro, 1908].

A mesma expressão no verso 1093 (qui finem uitai fecit) significa apenas "morrer", "terminar a vida", "viver o fim da vida". Munro, em comentário ao verso 943, remete a 1093 e afirma: the phrase is very common (1908, v.2, p. 221). Assim, o verso 943 poder-se-ia entender como: "Não é melhor terminar a vida e o sofrimento?", o que não é necessariamente uma sugestão de suicídio. Significa apenas que, visto que a morte nada é para nós, é melhor morrer que sofrer ou ficar à espera do sofrimento.

Há outras ocorrências de facio no terceiro livro do poema, com o sentido de "imaginar", "supor", "admitir"; por exemplo, no verso 626:

quinque, ut opinor, eam faciundum est sensibus auctam,

é de cinco sentidos que, na minha opinião, se deve imaginá-la provida;

ou no verso 878:

sed facit esse sui quiddam super inscius ipse,

mas, ele próprio inconsciente, supõe que algo dele sobrevive. 
Há, principalmente uma ocorrência no primeiro livro (655), em que o sentido de "admitir" me parece claro:

[...] si faciant admixtum rebus inane,

se admitirem o vazio misturado nas coisas.

Enfim, este é o teor da terceira parte da argumentação do livro III do De rerum natura: o homem é um ser da natureza e, como tal, a ela deve submeter-se; e deveria admitir com a mesma tranqüilidade o nascer e o morrer.

A verdade é que, em geral, não está o homem satisfeito com a vida mas não aceita a morte: quer viver, na esperança, talvez, de melhores dias, e enfrenta sofrimentos causados pelo medo, pelo amor, pela ambição. E não se lembra (mas deveria lembrar-se) de que a morte, fim do sofrer e do lutar, é lei comum: caem reis e senhores do mundo exatamente como caem os escravos. Morreram Anco, Xerxes e Cipião; e Homero; e Demócrito e Epicuro (III 1024-44). E aqui se encontra o terceiro documento que os sábios invocam para afirmar que Lucrécio aconselha ou pelo menos aprova o suicídio (1039-41):

\section{Denique Democritum postquam matura uetustas admonuit memores motus languescere mentis, sponte sua leto caput obuius optulit ipse,}

Afinal, depois que a madura velhice chamou a atenção a Demócrito para o fato de que os movimentos da memória e da mente começavam a enfraquecer, ele próprio espontaneamente ofereceu a cabeça à morte, indo-lhe ao encontro.

Lemos em Diógenes Laércio (IX 43) que Demócrito, muito idoso e quase morto, haveria conseguido sobreviver às Tesmofórias e que, após as festas, "deixou ir-se a vida". Não vem ao caso discutir se deixar ir-se a vida é ou não o mesmo que "matar-se". O que importa é perceber o tom em que o Poeta menciona a morte do filósofo. Não lhe vejo nem aprovação, como pretendem alguns, nem mágoa; vejo apenas o relato, e não posso afirmar, ao menos por enquanto, que o Poeta aconselhe ou aprove o suicídio.

Com relação ao pensamento do Mestre a respeito da morte voluntária, dois são os documentos mais citados.

Primeiro documento (Sententia Vaticana 9).

Diz Epicuro que a necessidade é um mal, porém que não há nenhuma necessidade de viver na necessidade: Kakòn anágke, all'oudemía anágke zên metà anágkes.

Ora, isso, ao meu ver, não é uma aceitação do suicídio; e muito menos ainda uma indução a ele. Como assinala Conche (Conche, 1977, p.249, n. 1), deve entender-se que o homem poderá sempre escapar à necessidade pela morte (o que também se lê em Cícero e Sêneca). Entretanto, o pensamento de Epicuro não é para a morte que se volta, e sim para a vida. Visto que é livremente que se morre, é livremente que se vive, pois o ato livre de morrer faz par com o ato livre de viver. Em outras palavras: se pode morrer quando quiser, o vivo está vivo porque quer. E a sua vida há de ser coerente com o seu querer.

Segundo documento (Carta a Meneceu $\$ 125-7$ ).

Diz o Mestre que a multidão teme a morte ora como o maior dos males, ora como a cessação da vida. Que o sábio, ao contrário, não teme o não viver: pois nem lhe pesa viver nem considera um mal o não viver. E que é tolo aquele que exorta o jovem a viver bem e o ancião a morrer bem; tolo não só por causa do prazer de viver mas também porque são o mesmo viver bem e morrer bem. E que muito pior ainda é aquele que diz que é belo "não haver nascido", mas que, "se nascemos é belo transpor logo as portas do Hades" 4. E conclui o Mestre: ei mèn gàr pepoithõs toûtò phesin, põs ouk apérkhetai ek toû zên;, "se está convencido do que diz, por que não deixa a vida?"

Ora, isto, menos ainda que uma sugestão de suicídio, seria até o contrário. E quando 
pergunta o Mestre "por que não deixa a vida aquele que considera belo transpor logo as portas do Hades", apenas salienta a contradição que.se encontra nos homens - mas não diz que o melhor é sair da vida.

O grande problema na interpretação dos escritos de Epicuro reside num duplo fato: 1) o desaparecimento da quase totalidade de sua obra; 2) a interpretação dos que tiveram acesso a ela.

Por exemplo, escreve Cícero no De finibus (I 19,62): Sapiens non dubitat si ita melius sit migrare de uita "se for melhor, o sábio não hesitará em sair da vida": e atribui a idéia ao epicurismo. Escreve, ainda, nas Tusculanae disputationes (V 41, 118):

Aut enim fruatur aliquis pariter cum aliis uoluptate potandi aut, ne sobrius in uiolentiam uinulentorum incidat, ante discedat. Sic iniurias fortunae quas ferre nequeas defugiendo relinquas. Haec eadem quae Epicurus totidem uerbis dicit Hieronymus,

ou sinta alguém o prazer de beber juntamente com os outros, ou antes se afaste para que, sóbrio, não venha a sofrer violência de ébrios. Assim, também, abandonem-se os reveses da fortuna que não se é capaz de suportar. Isso mesmo, que diz Epicuro, Jerônimo diz com as mesmas palavras ${ }^{5}$.

Esses e outros documentos de Cícero parece-me que seria suficiente dizer que são interpretações do pensamento do Mestre. E, como assinala Giussani (Giussani, 1896, p. lxxvii), ao comentar a doutrina moral de Epicuro, há certos pontos que Cícero e Plutarco não entendem, nem os entendem os modernos que vão direto a Cícero e Plutarco à procura de explicação.

A verdade é que, opositor feroz do epicurismo, o Orador imputa a Epicuro o conselho ao suicídio, que ele mesmo ora desaprovaria, ora consideraria imoral, ora consideraria como refúgio último que se procura se a dor é insuportável. Por exemplo em De finibus (I 15,49.19,62; II 29,945) e Tusculanae disputationes (II 27,67; V 41, 118), como também em Cato Maior (20,72).

Não obstante, em geral se interpreta a posição epicurista em face do suicídio a partir das afirmações de Cícero. Conheceria ele um texto que não conhecemos? Ou interpreta mal os que conhecemos? Ou se confunde a noção epicúrea com a noção estóica? Diz o Orador: Sapientis esse aliquando officium excedere e uita, cum beatus sit, "Às vezes é dever do sábio sair da vida, mesmo que seja feliz” (De fin.III 18,60-1). Mas isso é estóico (DL VII 130).

Entretanto, lê-se em Diógenes Laércio (X 119), que cita Epicuro a propósito do comportamento do sábio: Allà kaì perothénta tàs ópseis mê exáxein autón toû biou, "mas, ainda que tenha perdido a visão, não sairá da vida".

Ora, Diógenes Laércio parece estar mais próximo do pensamento do Mestre, que teria afirmado: Mikròs pantápasin hõi pollaì aitìai eúlogoi eis exagogèn biou, "é o menor de todos aquele para quem muitas são as boas razões para sair da vida" (Sent. Vat. 38).

Não podemos ignorar que o epicurismo é a filosofia menos bem entendida do mundo. $\mathrm{O}$ epicurista, no sentido moderno do termo, nada tem a ver com o Jardim: nem com a phrónesis nem com a ataraxia do Mestre. Moral da simplicidade e da moderação - em uma palavra, da conformidade com a natureza - , acabou-se por considerá-la moral (?) do prazer sem limites e do comportamento puramente animal. E, no entanto, se lhe atribui o que há de menos animal na natureza: o conselho ou a indução ao suicídio.

Para finalizar, penso no seguinte: o epicurismo é uma filosofia cujos valores maiores são o bom-senso, a coerência e a amizade. E me pergunto: um epicurista cometeria, aconselharia ou aprovaria o suicídio? Pode até entender e lamentar. Mas aprovar? Aconselhar?

\section{Notas}

1 - "Tranquiilidade" e "prazer" traduzem respectivamente euthymía e hedoné. Cf. DL IX 45. 
2 - Sobre o tempo, cf. De rerum natura, I 460.

3 - Na verdade, os mss $O Q$ trazem iacis, mas a correção, óbvia, como destaca Bailey (Bailey, 1950, p. 1153), é coerente com o verso 1093.

4 - Lugar-comum na literatura grega. Cf. Cic. Tusc. disp. I 48, 114 et seqs.

5 - Como assinala Humbert (Humbert, 1960, p. 181), trata-se de Jerônimo de Rodes, III a.C., cujo pensamento Cícero confundiu com o de Epicuro.

\section{Referências Bibliográficas}

CICÉRON. Tusculanes. Texte ét. par G. Fohlen \& trad. par J. Humbert. Paris: "Les Belles Lettres", 1960.

CONCHE, M. Épicure: lettres et maximes. Paris: Éd. de Mégare, 1977.

DIOGENES LAERTIUS. Livres of Eminent Philosophers. London: W. Heinemann, 1959.

GIUSSANI, C. Studi lucreziani. Torino: E. Loescher, 1896.

LUCRECE. De la nature. Texte ét. \& trad. par A. Ernout. Paris: “Les Belles Lettres”, 1978.

LUCRETI CARI, T. De rerum natura. Edit. by H. A. J. Munro. London: G. Bell, 1908.

LVCRETI CARI, T. De rerum natura. Edit. with Prol., Cr. Appar., Transl. \& Comm. by C. Bailey. Oxford: Clarendon, 1950.

Os pré-socráticos. Seleção de textos e supervisão de J. Cavalcante de Souza. São Paulo: Abril Cultural, 1973.

WISNIEWSKI, B. Prodicus et Épicure. L'Antiquité classique. Bruxelles: v. 25, p. 32-40, 1956.

NOVAK, M. G. La mort: est-ce le début ou la fin dans le De rerum natura? Classica, São Paulo, 7/8: 117-126, 1994/1995.

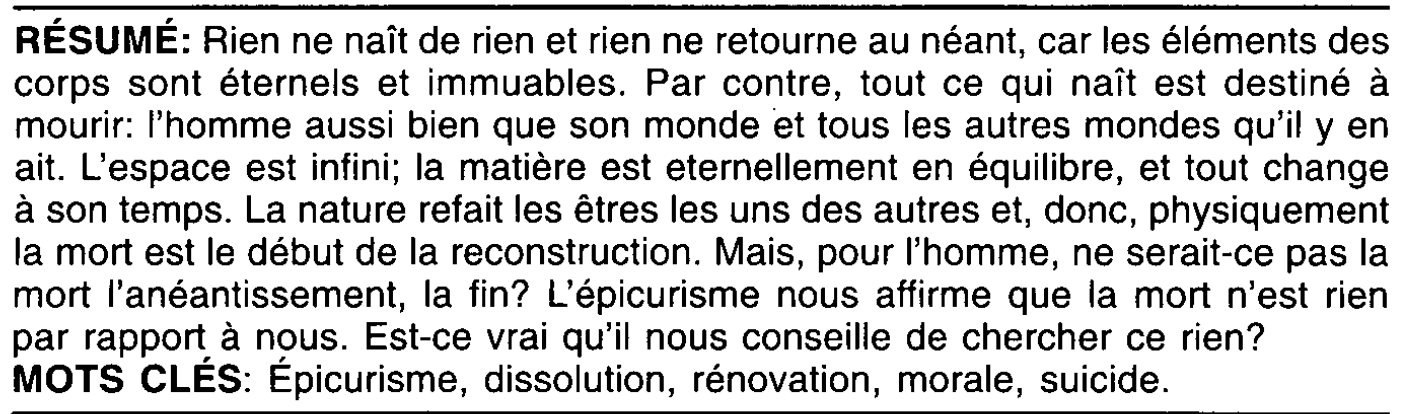

